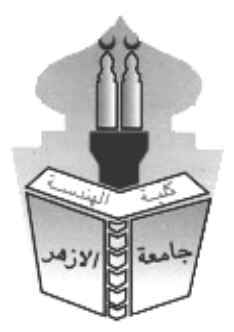

\title{
EXPERIMENTAL PROGRAM FOR REINFORCED CONCRETE RECTANGULAR COLUMNS CONFINED BY RECTANGULAR TIES
}

\author{
Mohamed Abdelzaher Mohamed Shanan', Ahmed Ragaey Hasan Anis ${ }^{2}$, Ashraf Hasan \\ El-Zanati ${ }^{2}$ and Kamal Ghamry Metwally ${ }^{2}$ \\ ${ }^{1}$ M.Sc. in Structural Engineering, Faculty of Engineering, Cairo University, \\ ${ }^{2}$ Reinforced Concrete, Structural Engineering, Department, Faculty of Engineering, Cairo \\ University
}

\begin{abstract}
This paper presents an experimental study of the behavior of reinforced concrete rectangular columns confined by rectangular ties under concentric loading. The study incorporates all the relevant parameters of confinement that have been observed to play important roles in column tests. These parameters include the concrete compressive strength, amount of confinement reinforcement, the tie spacing, the tie yield strength, longitudinal reinforcement distribution, the transverse reinforcement configuration and section geometry. Nineteen normal strength concrete rectangular columns with different concrete dimensions, different concrete compressive strength and confinement characteristics were designed, constructed and tested in this research. Significant gains in strength and ductility are recorded for the concrete core of well confined columns.
\end{abstract}

\section{KEYWORDS: Strength; Confinement; Ductility, Transverse Reinforcement Effect, Experimental Program.}

\section{INTRODUCTION}

The current design of reinforced concrete structures is concerned with the behavior of ultimate strength and ductility under severe loading conditions in view of the safety of structures and economy. One of the most important structural elements which play a significant role is the column. Columns are basically the main structural elements used to resist both vertical and lateral loads. The importance of ductility and associated energy absorption capacity of a structure in resisting earthquakes has long been recognized. The need for ductility was emphasized in recent years in light of the damages sustained by ductile buildings subjected to severe earthquakes. The previous researches have shown that the required ductility can be attained easily if the member behaves essentially in the flexure mode. Compression failure in reinforced concrete members is a brittle failure. It is evident that special design and detailing techniques must be employed to improve ductility of a column, which is a compression member. Previous researches have demonstrated that confinement of concrete column improves both the strength and ductility very significantly. In spite of a lot of researches that studied the stress-strain relationship and ductility of confined concrete columns, more experimental investigation especially for rectangular columns are needed, the overall objective of this paper is to establish characteristics of confined concrete columns through experimental research. The columns investigated by this paper classified as short columns, not affected by secondary stresses. 


\section{Test Program:}

A comprehensive experimental program was conducted to investigate the behavior of concrete columns confined with rectilinear reinforcement. The test program included a total of nineteen rectangular columns subjected to monotonically increasing concentric compression. Test specimens were designed to investigate the influence of main parameters of confinement. The parameters investigated are including cross-sectional shape, concrete strength, volumetric ratio, spacing of transverse reinforcement, longitudinal reinforcement distribution, transverse reinforcement arrangement, and yield strength of transverse reinforcement. A total of nineteen rectangular columns were prepared for testing. The columns were labeled as $\mathrm{C}-1$ up to $\mathrm{C}-19$. The columns were divided into two groups based on dimensions; the first group had $200 \mathrm{~mm} \times 400 \mathrm{~mm}$ rectangular cross-section, and $1500 \mathrm{~mm}$ height. The second group had $200 \mathrm{~mm} \times 300 \mathrm{~mm}$ rectangular cross-section, and $1500 \mathrm{~mm}$ height. The columns specimens were casted horizontally in four sets, while each set had a different batch of concrete with different compressive strength. The columns were confined with four different reinforcement configurations. Column geometry and tie configurations are as shown below in Fig.1.
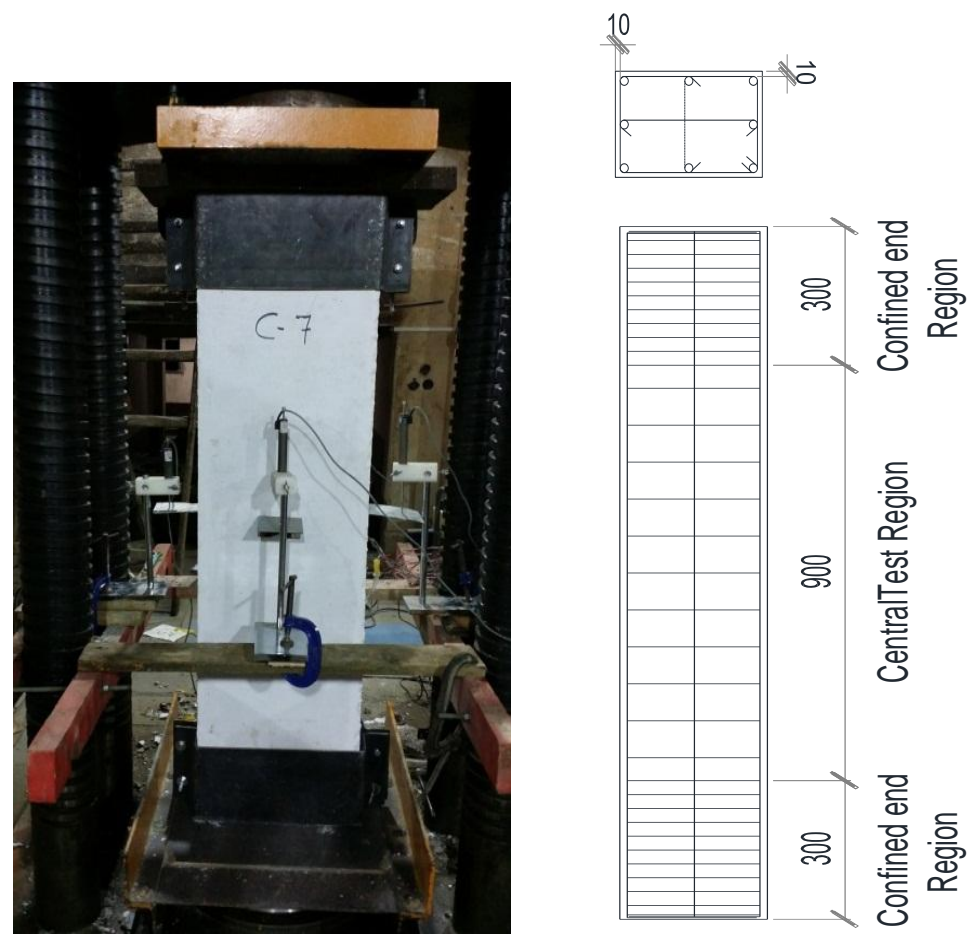
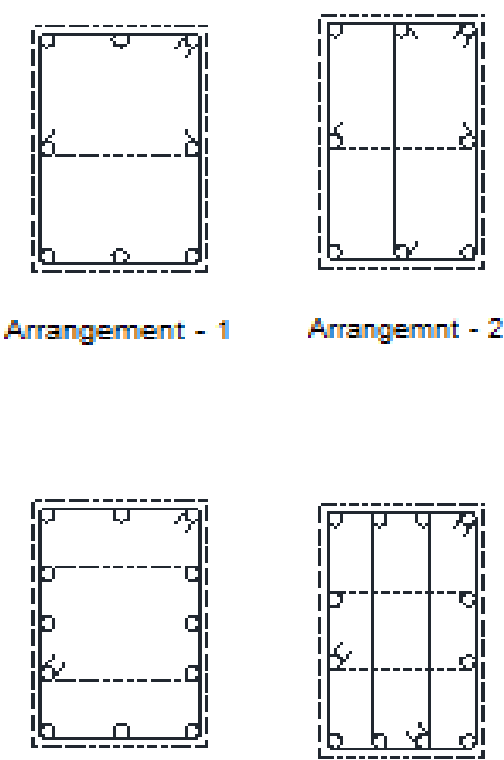

Arrangement - 3

Arrangement - 4

Fig. 1: Cross sectional arrangements and section geometry of tested columns

\subsection{Material Properties}

\subsubsection{Concrete}

Four different mix designs were used for four batches of concrete were produced in the Concrete Research Laboratory of the faculty of engineering, Cairo University. Strength and workability were the main criteria in mix designs. Suitable water-cement ratio (w/c) and cement content were used to achieve the strength level required. Normal Portland Cement and local aggregates were also used in all batches, the silica fume used in some batches was in liquid form to obtain more strength for the columns specimens with dimension $200 \times 300 \mathrm{~mm}$. For each batch of concrete, at least six 150 x $150 \mathrm{~mm}$ concrete cubes were tested at the same time of testing of the corresponding columns specimens to determine the properties of unconfined concrete. The concrete compressive strengths $\left(f^{\prime}{ }_{c}\right)$ attained were $39.5,41.5,43.5$ and $47.5 \mathrm{MPa}$, while these values represent $80 \%$ from the concrete compressive strength attained by standard cubes. 


\subsubsection{Steel}

The longitudinal reinforcement used was $10 \mathrm{~mm}, 12 \mathrm{~mm}$ and $18 \mathrm{~mm}$ diameter deformed bars. Three different grades and sizes of reinforcing steel were used as lateral reinforcement. The lateral steel used consisted of $10 \mathrm{~mm}$ diameter deformed bars, two different grades of $6 \mathrm{~mm}$ and $8 \mathrm{~mm}$ diameter plain bars. The mechanical properties for the tested specimens were tested in the Material Testing Lab of the faculty of engineering, Cairo University, as mentioned below in table (1), and the Properties of tested specimens are as shown below in table (2) .

Table 1: Mechanical Properties of Steel Bars.

\begin{tabular}{|c|c|c|c|c|c|}
\hline Model no. & $\begin{array}{c}\text { Nominal } \\
\text { diameter } \\
(\mathbf{m m})\end{array}$ & $\begin{array}{c}\text { sectional } \\
\text { area } \\
(\mathbf{m m})\end{array}$ & $\begin{array}{c}\text { Actual } \\
\text { diameter } \\
(\mathbf{m m})\end{array}$ & $\begin{array}{c}\text { Yield stress } \\
(\mathbf{N} / \mathbf{m m})\end{array}$ & $\begin{array}{c}\text { Ultimate } \\
\text { tensile } \\
\text { strength } \\
(\mathbf{N} / \mathbf{m m})\end{array}$ \\
\hline 1 & 6 & 29.55 & 6.13 & 291 & 433 \\
\hline 2 & 8 & 52.64 & 8.19 & 331 & 469 \\
\hline 3 & 10 & 79.01 & 10.03 & 534 & 665 \\
\hline 4 & 12 & 111.67 & 11.92 & 501 & 606 \\
\hline 5 & 18 & 256.62 & 18.07 & 361 & 655 \\
\hline
\end{tabular}

Table 2: Properties of Tested Specimens

\begin{tabular}{|c|c|c|c|c|c|c|c|c|c|c|}
\hline \multirow{2}{*}{ 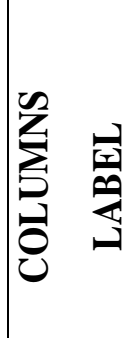 } & \multirow{2}{*}{ } & \multirow{2}{*}{ 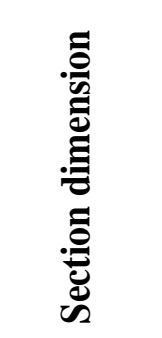 } & \multicolumn{2}{|c|}{$\begin{array}{l}\text { Longitudinal } \\
\text { Reinforcemen } \\
\mathbf{t}\end{array}$} & \multirow{2}{*}{$\frac{f_{c}^{\prime}}{\sum_{\Sigma}^{\sigma}}$} & \multirow{2}{*}{$\begin{array}{c}\text { fy.long } \\
\text { Мра }\end{array}$} & \multirow{2}{*}{$\begin{array}{l}\begin{array}{l}\text { fy. } \\
\text { ties }\end{array} \\
\sum_{\Sigma}^{\circ}\end{array}$} & \multirow{2}{*}{ 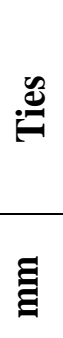 } & \multirow{2}{*}{$\begin{array}{l}\mathbf{S} \\
\Xi\end{array}$} & \multirow{2}{*}{$\begin{array}{c}\rho \\
\text { ties } \\
\%\end{array}$} \\
\hline & & & $\stackrel{\dot{0}}{Z}$ & $\begin{array}{c}\text { Diam. } \\
\text { mm }\end{array}$ & & & & & & \\
\hline $\mathrm{C}-1$ & 4 & $200 \times 400$ & 12 & 12 & 41.5 & 501 & 331 & 8 & 80 & 2.25 \\
\hline C -2 & 1 & $200 \times 400$ & 4,4 & 10,18 & 41.5 & 534,361 & 331 & 8 & 80 & 1.07 \\
\hline$C-3$ & 3 & $200 \times 400$ & 4,4 & 10,18 & 41.5 & 534,361 & 331 & 8 & 80 & 1.48 \\
\hline C - 4 & 3 & $200 \times 400$ & 12 & 12 & 41.5 & 501 & 291 & 6 & 45 & 1.41 \\
\hline$C-5$ & 2 & $200 \times 400$ & 12 & 12 & 41.5 & 501 & 331 & 8 & 80 & 1.38 \\
\hline$C-6$ & 3 & $200 \times 400$ & 12 & 12 & 39.5 & 501 & 331 & 8 & 60 & 1.97 \\
\hline$C-7$ & 3 & $200 \times 400$ & 12 & 12 & 39.5 & 501 & 331 & 8 & 80 & 1.48 \\
\hline$C-8$ & 2 & $200 \times 400$ & 4,4 & 10,18 & 39.5 & 534,361 & 534 & 10 & 100 & 1.66 \\
\hline C - 9 & 4 & $200 \times 400$ & 12 & 12 & 39.5 & 501 & 331 & 8 & 120 & 1.50 \\
\hline C-10 & 3 & $200 \times 400$ & 10 & 12 & 39.5 & 501 & 534 & 10 & 125 & 1.42 \\
\hline C-11 & 1 & $200 \times 300$ & 4,4 & 10,18 & 47.5 & 534,361 & 331 & 8 & 80 & 1.21 \\
\hline C-12 & 2 & $200 \times 300$ & 4,4 & 10,18 & 43.5 & 534,361 & 534 & 10 & 100 & 2.14 \\
\hline C-13 & 3 & $200 \times 300$ & 12 & 12 & 43.5 & 501 & 534 & 10 & 125 & 1.60 \\
\hline C-14 & 3 & $200 \times 300$ & 4,4 & 10,18 & 43.5 & 534,361 & 331 & 8 & 100 & 1.37 \\
\hline C-15 & 3 & $200 \times 300$ & 12 & 12 & 47.5 & 501 & 331 & 8 & 80 & 1.67 \\
\hline C-16 & 4 & $200 \times 300$ & 12 & 12 & 43.5 & 501 & 331 & 8 & 80 & 2.47 \\
\hline C-17 & 3 & $200 \times 300$ & 12 & 12 & 47.5 & 501 & 331 & 8 & 50 & 2.67 \\
\hline C-18 & 3 & $200 \times 300$ & 10 & 12 & 43.5 & 501 & 331 & 8 & 80 & 1.67 \\
\hline C-19 & 2 & $200 \times 300$ & 12 & 12 & 43.5 & 501 & 331 & 8 & 110 & 1.79 \\
\hline
\end{tabular}




\subsection{Instrumentation}

The specimens were instrumented with Linear Voltage Displacement Transducers LVDT to measure axial deformations. A total of four LVDT's, one on each column face. This enabled continuous data recording, even after the spalling of concrete cover. Electric strain gauges were placed on lateral and longitudinal reinforcement to measure steel strains. Most of the column specimens had eight gauges placed on tie steel, four on the central tie, and two on each of the ties immediately above and below. as shown below in Fig. 2.

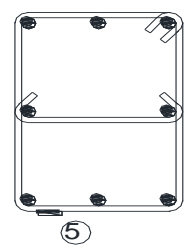

Above Central tie immediately

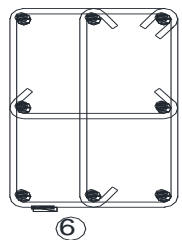

Above Central tie immediately

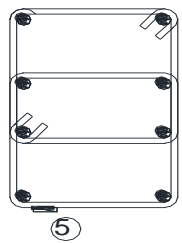

Above Central tie immediately

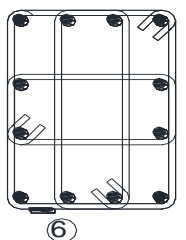

Above Central tie immediately

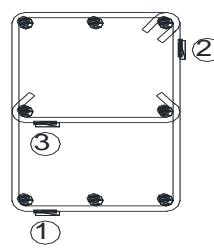

Central tie

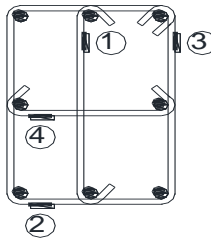

Central tie

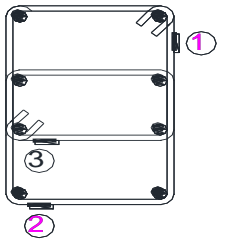

Central tie

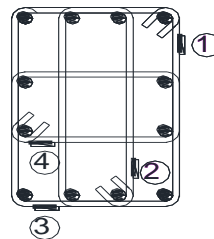

Central tie

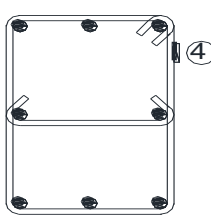

Below Central tie immediately

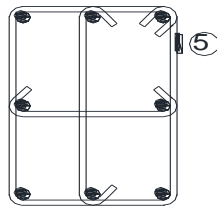

Below Central tie immediately

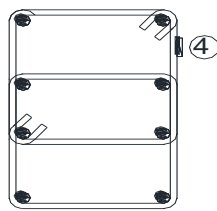

Below Central tie immediately

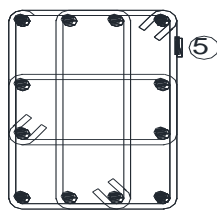

Below Central tie immediately

Fig. 2: Location of strain gages on lateral steel

A pressure transducer was used to measure the applied load. The LVDT readings, steel strains, and applied load were recorded using a Data Acquisition System and a microcomputer as illustrated below in Fig. 3. 

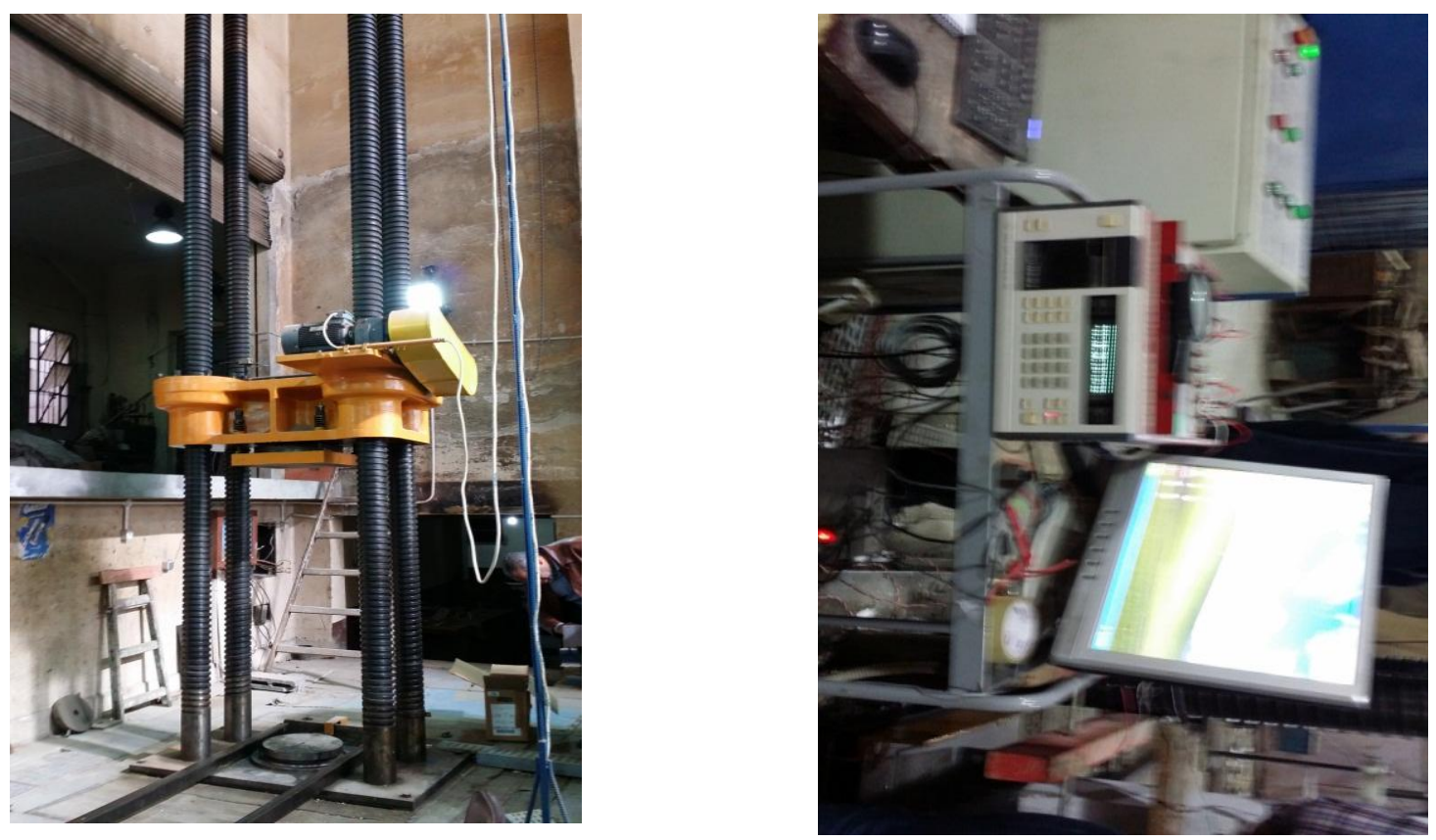

Fig. 3: Testing machine and Recorded test data

\subsection{Test Procedure}

The specimens were tested under monolithically increasing concentric compression using the AMSLER 5,000 kN capacity compression testing machine, located at the Concrete Research Laboratory of the faculty of engineering, Cairo University was used. The columns also were prepared in the same Laboratory. The testing machine is shown above in Fig. 3. Four LVDTs were mounted on four sides of the column, at column mid-height. The LVDTs were connected to the computer unit of the testing machine, and strain gauges were connected to the data acquisition system. The columns were placed and adjusted between the heads of the machine with its centerlines coinciding with the centerline of the machine base. The load was applied by compressing the column between the plate at top of the machine and the plate under the column. To insure that the failure would occur in the test region of the tested specimens, the tapered ends of each specimen were further confined with end bracket steel $15 \mathrm{~mm}$ thickness. The initial load was applied slowly, and the deflections on four sides of the column were monitored. If the deflections were not approximately the same, this was an indication of the load not being concentric. The column was then unloaded to minimize the accidental end eccentricity as possible. This procedure continued until all four LVDT's indicated approximately the same reading, signifying that the initial load was concentric. Computer reading were taken at equal intervals up to the first peak. During the post peak response of the tested specimens, frequent readings were taken up to the rupture.

\subsection{Observed Behavior and Recorded Data}

The experimental observations made during column tests are presented and discussed in this section, along with the raw data recorded. The data presented include axial force- axial strain relationships as recorded by LVDT's, and steel strains as recorded by strain gauges. The recorded data is then processed to obtain the behavior of confined concrete core and the effects of test parameters. Fig. 4 below illustrates axial load-axial strain relationships recorded during testing of columns, while the observed behaviors of these columns during testing are also shown in Fig. 5 below. The reinforced concrete specimens were reinforced with different reinforcement arrangements, and the specimens were continuously monitored during testing for development of surface cracks. These cracks eventually resulted in spalling of concrete cover, while large pieces of concrete cover were observed to separate from the core and spall 
off, suggesting that the spalling was due to instability of concrete cover rather than crushing of the shell concrete. Each column had four strain gauges located on corner bars. For most of columns, the formation of cracks was not uniform on all sides. Usually the cracks were observed on one side of the column, before resulting in spalling. The cracks soon propagated to other sides, causing complete spalling of the cover. The loading became approximately concentric after complete spalling of the cover. At this load stage, the applied load was resisted by concrete core and longitudinal reinforcement. Therefore, the post peak behavior varied depending on the confinement characteristics of the concrete core. The failure was associated with hoop fracture, buckling of longitudinal reinforcement, and crushing of concrete core. Most of the columns behaved in a fairly ductile manner, until the fracture of one or more ties. Once the first tie fractured, one or more longitudinal bars buckled causing the load to drop at a fast rate. All columns had strain gauges placed on longitudinal reinforcement. The results indicated a very good agreement between axial concrete strain and steel strains prior to the yielding of longitudinal steel as shown below in fig. 6 below. This indicates that there was no bond slip between steel and concrete. Buckling of longitudinal steel was not observed in columns with closely spaced lateral steel until after the fracture of transverse reinforcement. In columns with widely spaced lateral steel, however, longitudinal bars buckled between the ties prior to fracture. The axial load level at buckling varied depending on size and spacing of ties. Strains in ties were measured using electric strain gauges. According to typical axial load - lateral steel strain relationships as shown below in fig. 7 , it was observed that transverse reinforcement yielded after the peak load was reached.
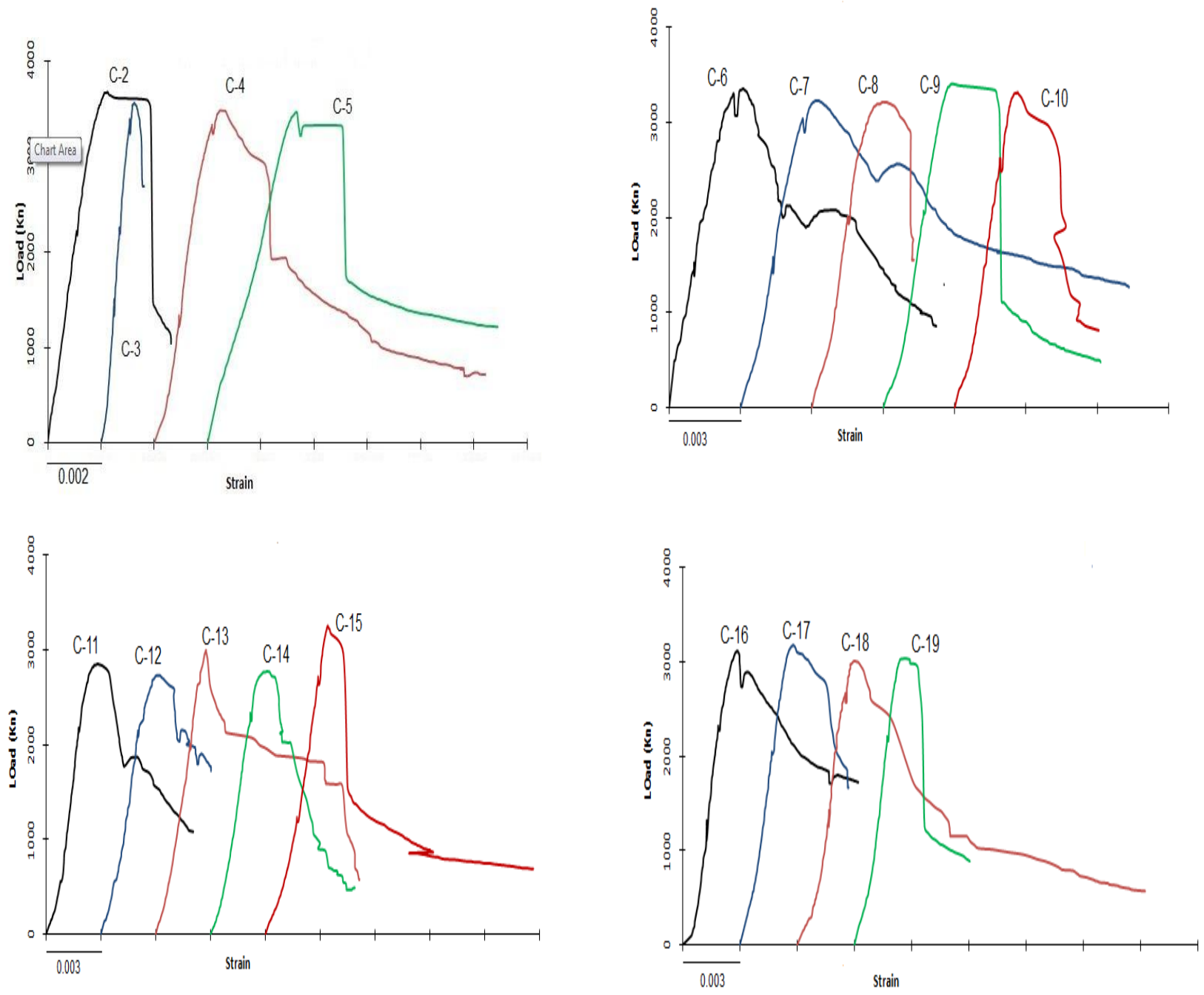

Fig. 4: Axial force axial strain relationship for all specimens 

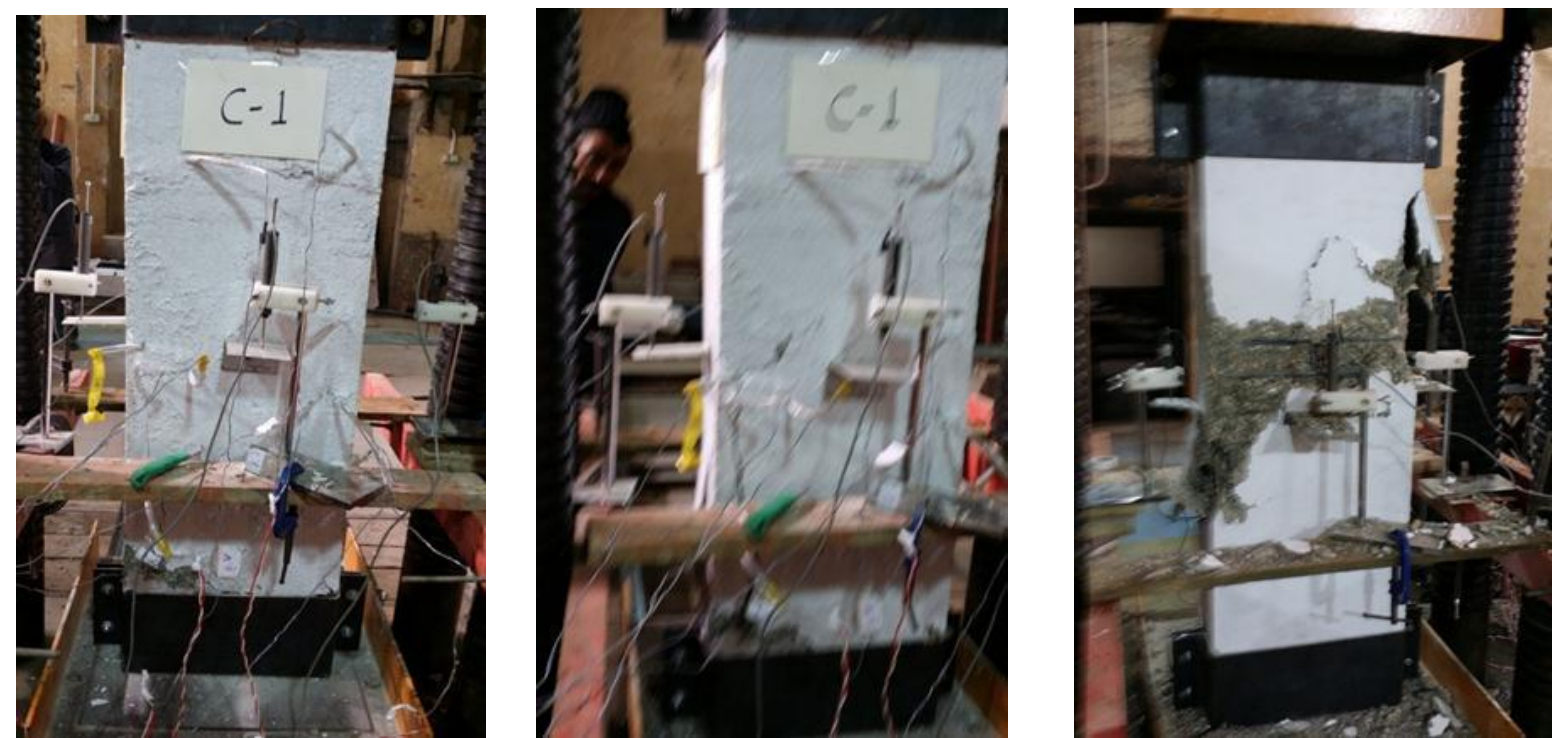

Fig. 5: Column behavior during stages of loading
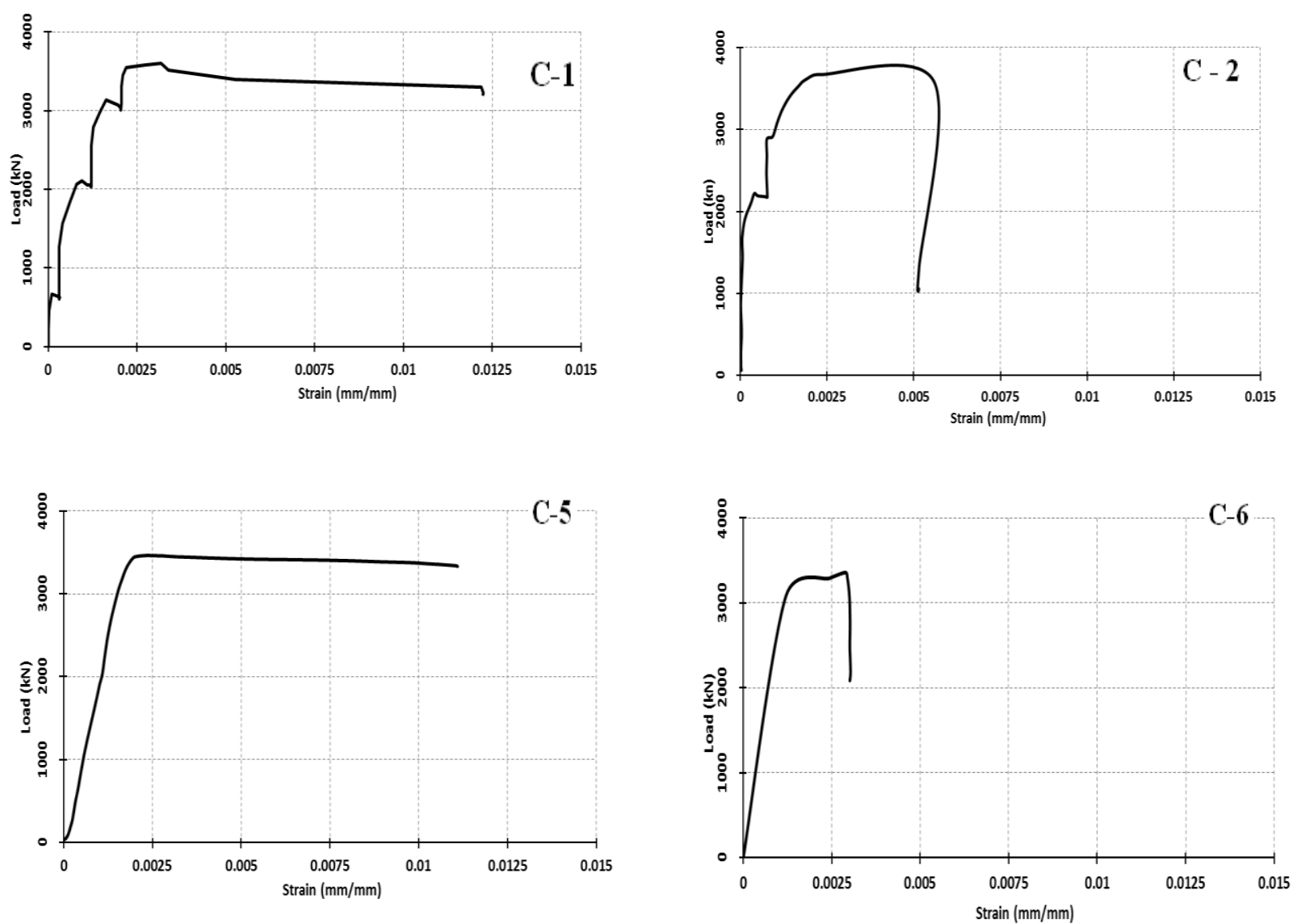

Fig. 6: Column load versus longitudinal steel strain 

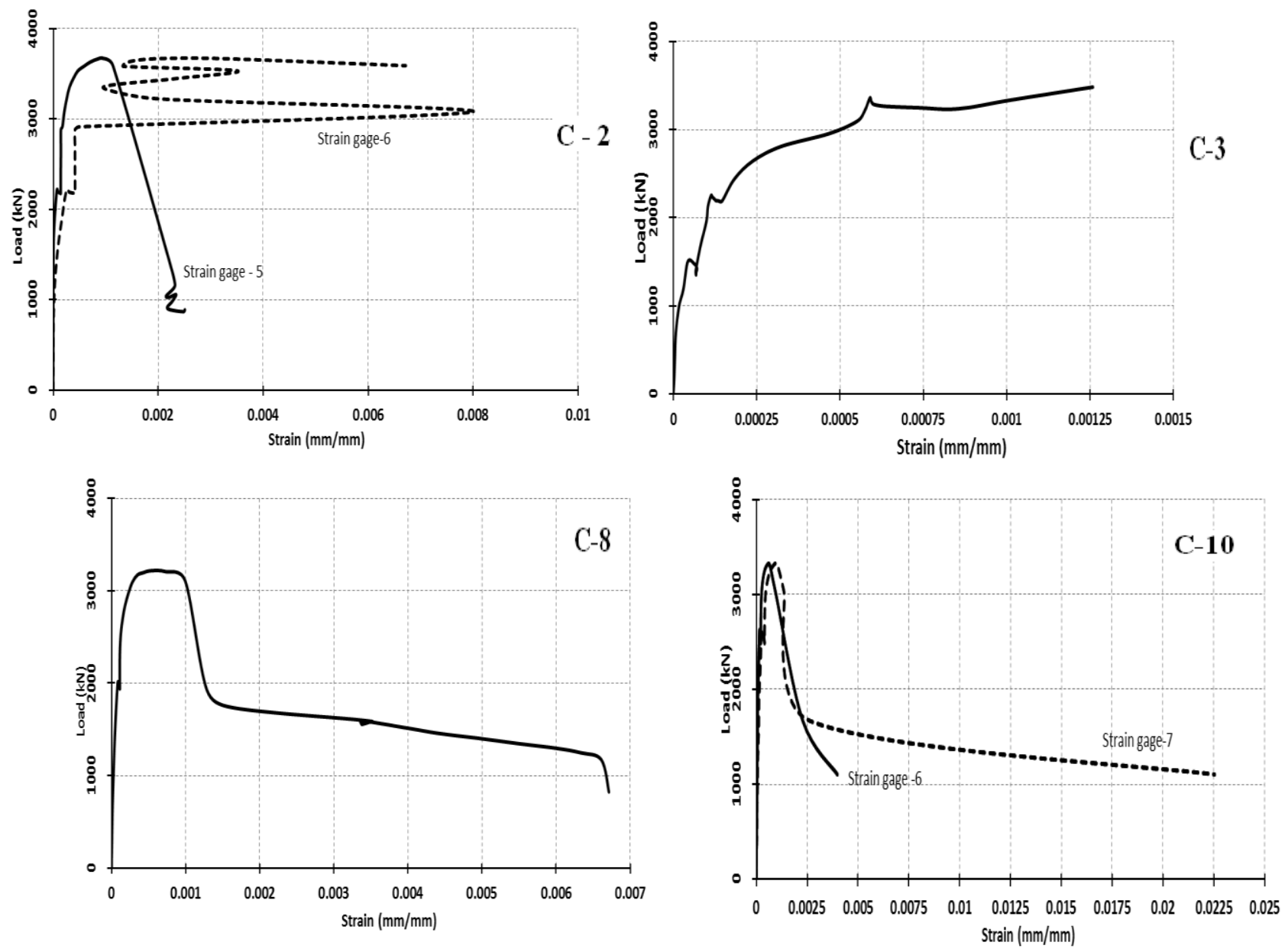

Fig. 7: Column load versus transverse steel strain for column

\subsection{Evaluation of Tested Columns}

To evaluate the effect of the various parameters on the behavior of the tested column specimens, two measures are strength and ductility of the tested specimen will be used.

\subsubsection{Evaluation of Column Strength}

The Column strength under concentric loading was recorded during testing. Experimental observations indicated that cover spalling had occurred prior to the attainment of the load capacity; therefore, the maximum load was resisted by the concrete core, including the contribution of longitudinal reinforcement. Table (3) below, contains recorded strengths of rectangular columns. According to the previous researches, $0.85 f^{\prime}{ }_{c}$ will be used to represent the in-place strength of unconfined concrete in columns. Strength enhancement due to confinement was measured by effective confinement index (Ks), by comparing strengths of Core $\left(f_{c c}^{\prime}\right)$, and unconfined concrete $\left(f^{\prime}{ }_{c o}\right)$. (Ks) was computed by equation (1) shown below. The core capacity was established by subtracting the contribution of longitudinal reinforcement from the recorded column capacity. The ratios of confined to unconfined concrete strengths are listed in table (3) below. It's indicating up to $42 \%$ increase in concrete strength due to confinement. $\quad \mathrm{Ks}=f^{\prime}{ }_{c o} / f^{\prime}{ }_{\text {oo }}$ 
Table 3: Experimental strength and confinement index ( Ks ) for columns

\begin{tabular}{|c|c|c|c|c|c|c|c|}
\hline \multirow{2}{*}{ 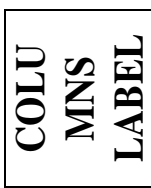 } & \multirow{2}{*}{$\begin{array}{c}\text { Reinforce } \\
\text { ment } \\
\text { Arrange } \\
\text { ment }\end{array}$} & \multirow{2}{*}{$\frac{f_{c}^{v}}{(\mathbf{M P a})}$} & \multirow{2}{*}{$\frac{P_{\text {Test }}}{(\mathbf{K n})}$} & \multirow{2}{*}{$\frac{P_{C C}}{(K n)}$} & \multirow{2}{*}{$\frac{f^{\prime}{ }_{\sigma e}(\exp )}{(\mathbf{M P a})}$} & \multirow{2}{*}{$\begin{array}{c}f_{c o}^{\prime}=\mathbf{0 . 8 5} f^{\prime}{ }_{c} \\
\text { (MPa) }\end{array}$} & \multirow{2}{*}{ Ks } \\
\hline & & & & & & & \\
\hline C- 1 & 4 & 41.5 & 3602 & 2931 & 45.8 & 35.28 & 1.30 \\
\hline C- 2 & 1 & 41.5 & 3670 & 3141 & 49.1 & 35.28 & 1.39 \\
\hline C- 3 & 3 & 41.5 & 3557 & 3028 & 47.3 & 35.28 & 1.34 \\
\hline C- 4 & 3 & 41.5 & 3480 & 2808 & 43.2 & 35.28 & 1.22 \\
\hline C- 5 & 2 & 41.5 & 3463 & 2792 & 43.6 & 35.28 & 1.24 \\
\hline C- 6 & 3 & 39.5 & 3359 & 2688 & 42.0 & 33.58 & 1.25 \\
\hline C- 7 & 3 & 39.5 & 3232 & 2561 & 40.0 & 33.58 & 1.19 \\
\hline C- 8 & 2 & 39.5 & 3218 & 2689 & 42.7 & 33.58 & 1.27 \\
\hline C- 9 & 4 & 39.5 & 3408 & 2737 & 42.8 & 33.58 & 1.27 \\
\hline C- 10 & 3 & 39.5 & 3318 & 2758 & 43.9 & 33.58 & 1.31 \\
\hline C- 11 & 1 & 47.5 & 2857 & 2327 & 49.7 & 40.38 & 1.23 \\
\hline C-12 & 2 & 43.5 & 2733 & 2204 & 47.1 & 36.98 & 1.27 \\
\hline C- 13 & 3 & 43.5 & 2999 & 2328 & 49.8 & 36.98 & 1.35 \\
\hline C- 14 & 3 & 43.5 & 2777 & 2248 & 48.0 & 36.98 & 1.30 \\
\hline C- 15 & 2 & 47.5 & 3258 & 2587 & 55.3 & 40.38 & 1.37 \\
\hline C- 16 & 4 & 43.5 & 3120 & 2449 & 52.3 & 36.98 & 1.42 \\
\hline C- 17 & 3 & 47.5 & 3183 & 2512 & 53.7 & 40.38 & 1.33 \\
\hline C- 18 & 3 & 43.5 & 3014 & 2454 & 52.5 & 36.98 & 1.42 \\
\hline C- 19 & 4 & 43.5 & 3037 & 2366 & 50.6 & 36.98 & 1.37 \\
\hline
\end{tabular}

\subsubsection{Evaluation of Column Deformability}

Column deformability reflects the ability of columns to deform without a significant loss of strength. Deformability of columns tested in this study program was investigated by the ductility. The ductility of columns was evaluated in terms of the axial strain ductility ratio which is the ratio between the axial strains of confined core at certain level of loading on the descending part to the axial strain of the confined core at the ultimate $\operatorname{strength}^{[3]}$. In this study, the used strain ductility ratio is $u_{\mathrm{gs} d}$ and can be computed as follows:

$$
u_{85 d}=\epsilon_{85 d} / \epsilon_{00}
$$

$u_{85 d}=$ Axial strain ductility ratio corresponding to $\in_{85 d}$

$\epsilon_{85 d}=$ Axial strain corresponding to the $85 \%$ of the ultimate compressive load on the descending part

$\epsilon_{c o}=$ Axial strain corresponding to the ultimate compressive load. 
Table 4: Axial strain ductility ratio for the column

\begin{tabular}{|c|c|c|c|c|c|}
\hline Columns Label & $\begin{array}{c}\text { Reinforcement } \\
\text { Arrangement }\end{array}$ & $f^{\prime}{ }^{\prime}$ (Mpa) & $\varepsilon 85$ & Ecc & $u_{85 d}$ \\
\hline C - 1 & 4 & 41.5 & N/A & N/A & N/A \\
\hline$C-2$ & 1 & 41.5 & 0.00386 & 0.00226 & 1.71 \\
\hline$C-3$ & 3 & 41.5 & 0.00153 & .001253 & 1.22 \\
\hline C - 4 & 3 & 41.5 & 0.00397 & 0.00240 & 1.58 \\
\hline C - 5 & 2 & 41.5 & 0.00510 & 0.0033 & 1.55 \\
\hline C - 6 & 3 & 39.5 & 0.00378 & 0.0031 & 1.22 \\
\hline C - 7 & 3 & 39.5 & 0.00479 & 0.00325 & 1.48 \\
\hline C - 8 & 2 & 39.5 & 0.00469 & 0.00303 & 1.55 \\
\hline C - 9 & 4 & 39.5 & 0.00530 & 0.00286 & 1.62 \\
\hline $\mathrm{C}-10$ & 3 & 39.5 & 0.00517 & 0.00266 & 1.67 \\
\hline $\mathrm{C}-11$ & 1 & 47.5 & 0.00391 & 0.00283 & 1.29 \\
\hline $\mathrm{C}-12$ & 2 & 43.5 & 0.00407 & 0.00311 & 1.31 \\
\hline$C-13$ & 3 & 43.5 & 0.00323 & 0.00275 & 1.18 \\
\hline$C-14$ & 3 & 43.5 & 0.00396 & 0.00307 & 1.21 \\
\hline $\mathrm{C}-15$ & 2 & 47.5 & 0.00430 & 0.00341 & 1.26 \\
\hline$C-16$ & 4 & 43.5 & 0.00404 & 0.00286 & 1.59 \\
\hline$C-17$ & 3 & 47.5 & 0.00508 & 0.00329 & 1.54 \\
\hline C -18 & 3 & 43.5 & 0.00420 & 0.00300 & 1.40 \\
\hline C -19 & 4 & 43.5 & .003475 & 0.00266 & 1.31 \\
\hline
\end{tabular}

The results of $u_{85 d}$ shows that axial strain ductility ratio significantly increases with the increase of confinement factors as indicated above in table (4) for most of columns specimens.

\subsection{Effects of test variables on behavior of confined concrete}

The experimental program was designed to establish relationships between confinement parameters, and strength and ductility of concrete columns. In this section the effect of every parameter is studied separately to understand accurately the real relation and the actual effect of each variable.

\subsubsection{Concrete Compressive Strength}

From the experimental program results, Rectangular columns C-18 and C-15 with the same arrangement of longitudinal and lateral reinforcement had 43.5 and $47.5 \mathrm{MPa}$ concrete strength respectively. The results indicate that $43.5 \mathrm{MPa}$ concrete benefited more from the same confinement reinforcement and developed higher strength enhancement. Furthermore, the $43.5 \mathrm{MPa}$ concrete clearly showed better ductility characteristics than the companion concrete with 47.5 MPa as shown in table(3) and table (4). The comparisons described above indicate a consistent decrease in deformability with increasing concrete strength, therefore, if the same percentage of strength enhancement is desired, higher strength concrete columns are required to be confined more than those with lower strength concretes as shown below in Fig. 8.

Fig. 8: Effect of concrete strength

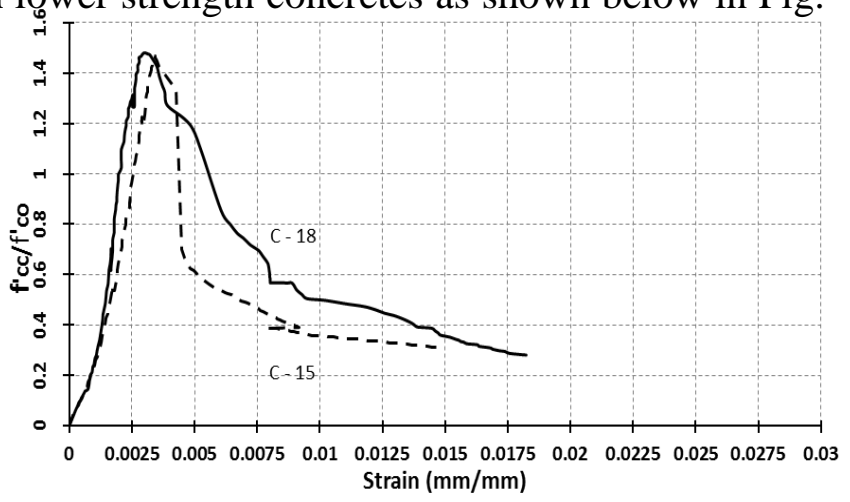




\subsubsection{Amount of Confinement Reinforcement}

From the experimental program results, comparing between the pairs of rectangular columns C-16 and C-19, also between the pairs of rectangular of columns C-15 and C-14 as shown above in table (3) and table (4), the results indicated that both strength and ductility of confined concrete increase with increasing the volumetric ratio of confinement as shown below in Fig. 9.

The comparisons described above indicated that both strength and ductility of confined concrete increase with an increase in volumetric ratio. Columns with increased lateral reinforcement are able to deform significantly with verv little drop in capacitv.
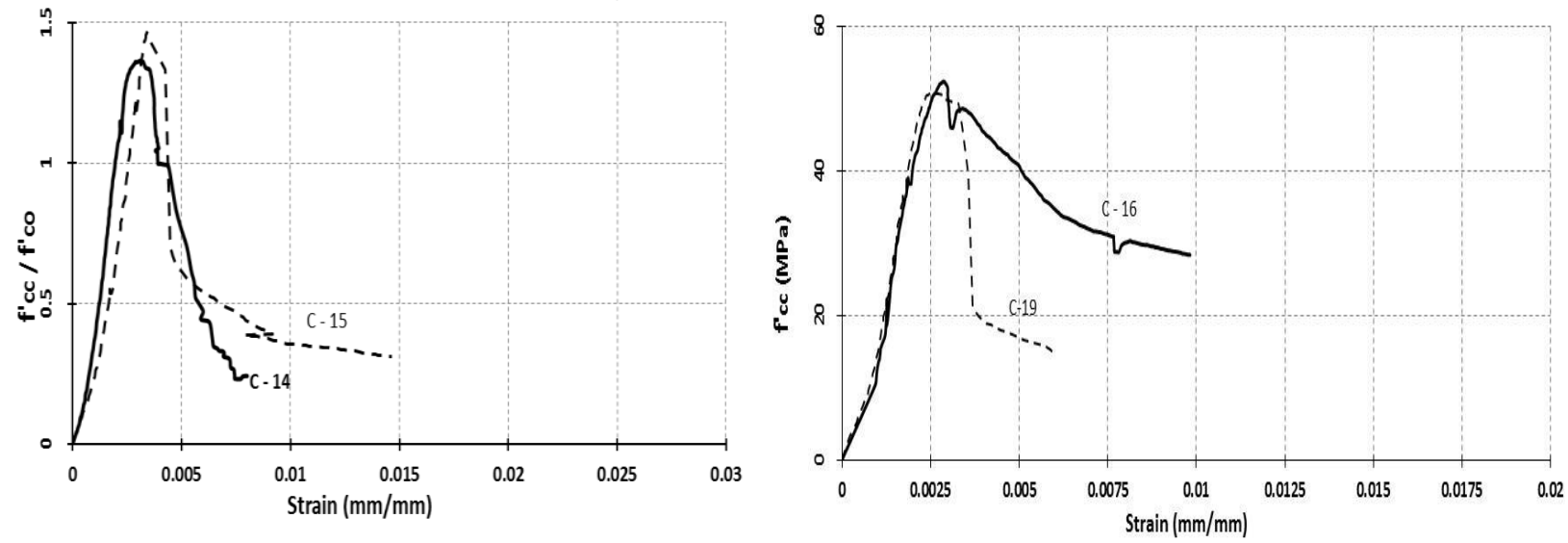

Fig. 9: Effect of volumetric ratio of transverse reinforcement

\subsubsection{Yield Strength of Transverse Reinforcement}

From the experimental program results, the effect of yield strength was investigated by testing two pairs of rectangular columns with the same volumetric ratio, but different yield strengths of lateral reinforcement. The comparisons as shown above in table (3) and table (4), indicated that the columns $\mathrm{C}-10$ confined with $534 \mathrm{MPa}$ lateral steel showed improved strength and ductility as compared to column C-7 with $331 \mathrm{MPa}$ lateral steel as shown below in Fig. 10 . According to typical axial load - lateral steel strain relationships, it was observed that the peak load was reached before transverse reinforcement reach to yield, it indicated that the yield strength of transverse reinforcement is not fully used for confinement effect and it is necessary to use an effective stress instead of the yield stress value to estimate the enhancement in confined strength and ductility, it is also noted that the effective stress value not dependent only on transverse steel yield stress, but it is significantly affected by concrete strength, amount of transverse reinforcen

Fig. 10: Effect of yield strength of transverse reinforcement

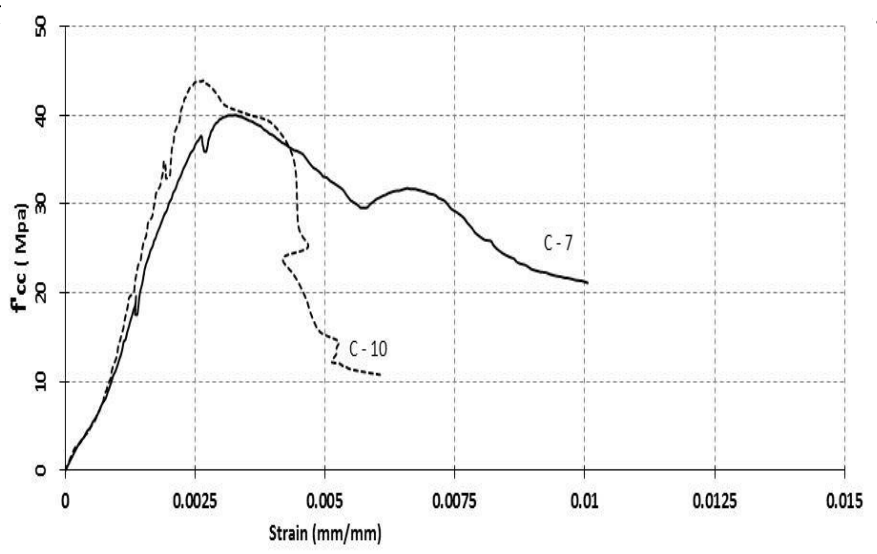

\subsubsection{Distribution of Longitudinal Steel and Resulting Tie Arrangement}

From the experimental program results, comparing between the rectangular columns C-7 and C-9, which have almost the same properties except the distribution of longitudinal steel and resulting tie arrangement, where the transverse reinforcement for column C-9 is well distributed around the perimeter of the concrete core more than column C-7. (as shown in 
table (3) and table (4)), the results indicated that both strength and ductility of confined concrete for column C-9 showed a better enhancement in confined concrete compressive strength and ductility characteristics more than C-7 as shown below in Fig. 11.

The comparisons described above indicate that, the arrangement of transverse reinforcement is an important parameter that affects distribution of confinement pressure. If the lateral force applied by transverse reinforcement on concrete is well distributed around the perimeter of the concrete core, the distribution of lateral pressure becomes almost uniform, improving the efficiency of confinement reinforcement. The arrangement of transverse reinforcement has been shown to have significant effects on strength and ductility of normal strength concrete columns.

Fig. 11: Effect of longitudinal steel and Resulting tie arrangement

\subsubsection{Tie Spacing}

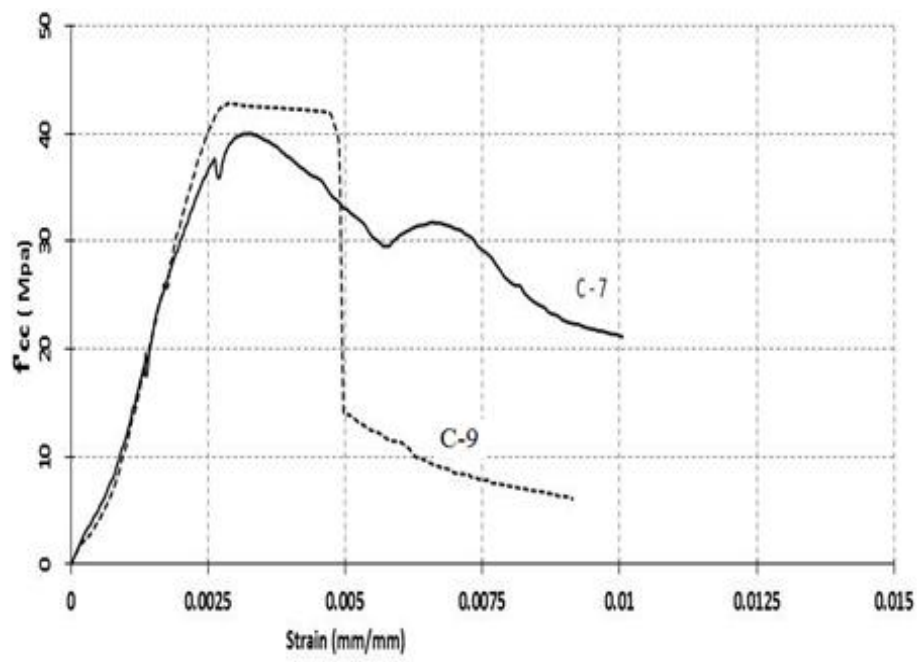

From the experimental program results, comparing between the pairs of rectangular columns C-4 and C-7, and also between the pairs of rectangular of columns C-18 and C-19 as shown above in table(3) and table (4), the results indicated that both strength and ductility of confined concrete increase with closer spacing of transverse reinforcement as shown below in Fig. 12. This comparison indicate that, spacing of transverse reinforcement is one of the important parameters that affect the distribution of confinement pressure, as well as the stability of longitudinal reinforcement. Behavior of columns with different tie spacing indicated that closer spacing of transverse reinforcement is found to increase the uniformity of lateral pressure and effectiveness of confinement reinforcement. The results also indicated that columns with wide tie spacing may not develop any confinement. Légeron and Paultre (2003) indicated that geometric confinement effectiveness coefficient which measures the effectiveness of the confinement reinforcement to confine concrete varies from 1 for a continuous tube to 0.0 when ties are spaced more than half the core cross section minimum dimension ${ }^{[3]}$. Concrete columns specimens tested by Yong et al. (1988) did not develop any effect of confinement when the tie spacing was increased to be equal to the section size ${ }^{[1]}$.
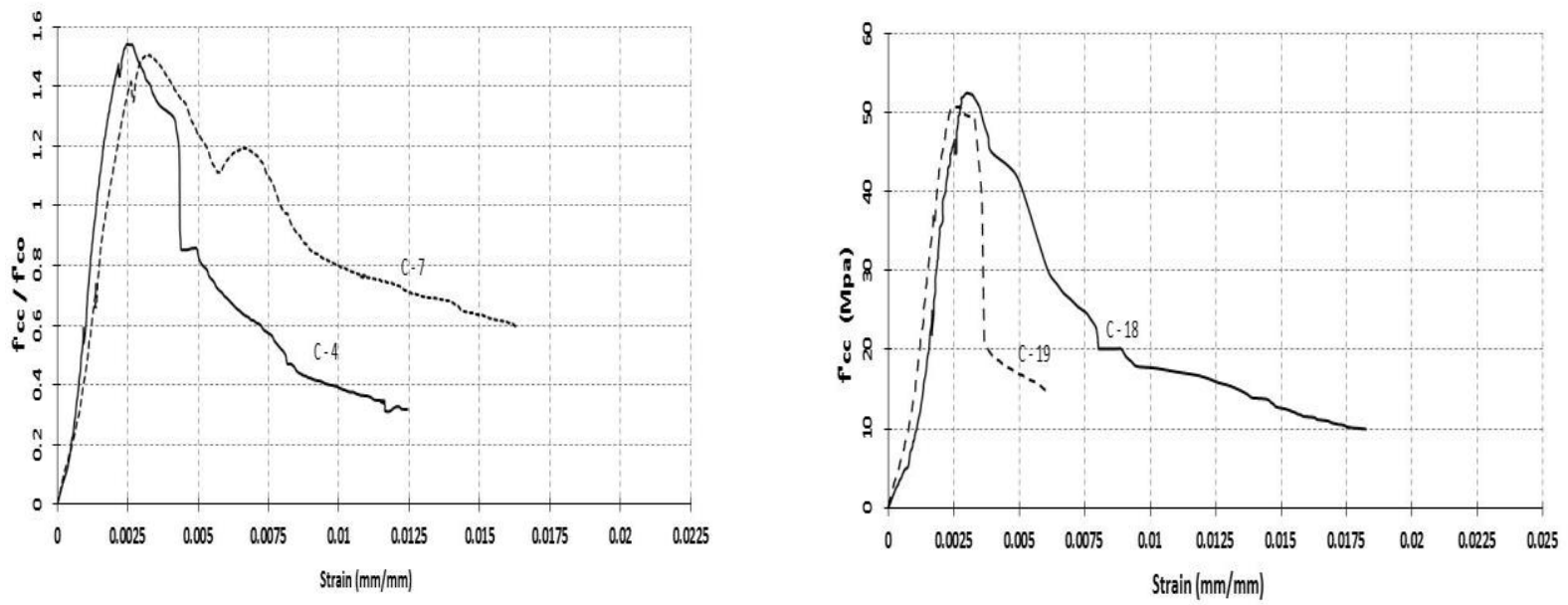

Fig. 12: Effect of tie spacing 


\subsubsection{Section Geometry}

From the experimental program results comparing between the pairs of rectangular columns C-6 and C-17 as shown above in table (3) and table (4), the results indicated that both strength and ductility of confined concrete for column C-17 with concrete section $200 \times 300 \mathrm{~mm}$ showed a better enhancement in confined concrete compressive strength and ductility characteristics more than C-6 with concrete section 200 x 400 mm as shown below in Fig. 13.

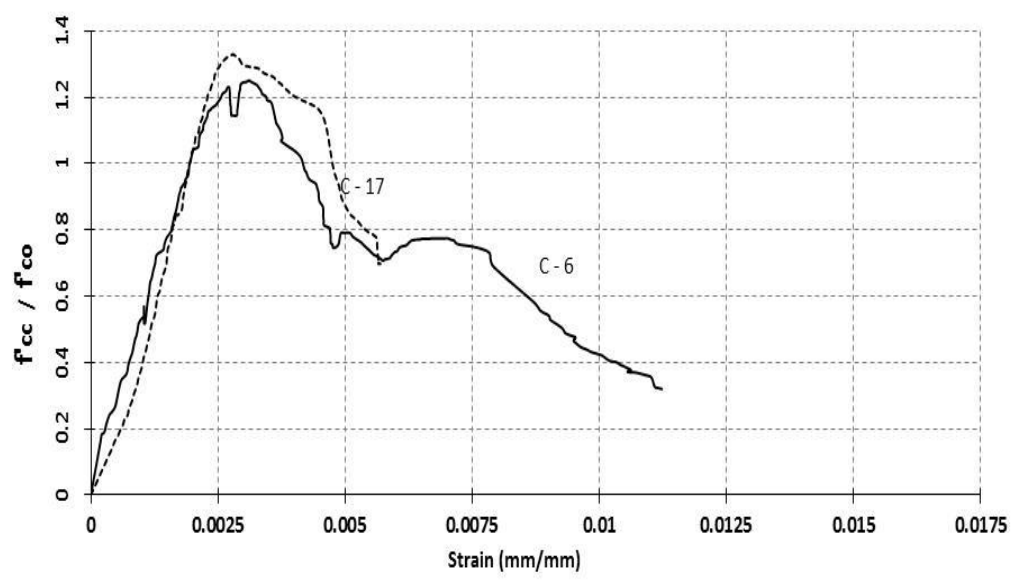

Fig. 13: Effect of section geometry

The results indicated that, the strength of confined concrete for square column showed a better enhancement more than rectangular columns, and the enhancement in confined strength decreases by increasing the ratio between the long direction and the short direction of rectangular columns.

\subsection{CONCLUSION}

This experimental research program has contributed to the fundamental understanding of the complex mechanism of confinement of reinforced concrete rectangular columns with rectangular ties. The following conclusions have been found.

- The effects of main confinement variables were studied with respect to strength and ductility gains. Increasing the concrete compressive strength results in an important decrease of the gains in strength and ductility of confined concrete. On the other hand, increasing the transverse reinforcement ratio significantly enhances the strength and ductility gains of the confined concrete. The transverse reinforcement ratio is the test variable with the most important beneficial effect on the stress-strain behavior of concrete.

- It was observed that the peak load was reached before transverse reinforcement reach to yield, it's indicated that the yield strength of transverse reinforcement is not fully used for confinement effect, and it's necessary to use an effective stress instead of the yield stress value to estimate the enhancement in confined strength and ductility. It is noted that the effective stress value not dependent only on transverse steel yield stress, but its significantly affected by concrete strength, amount of transverse reinforcement and vertical and horizontal spacing between ties.

- Arrangement of transverse reinforcement is an important parameter that affects distribution of confinement pressure. If the lateral force applied by transverse reinforcement on concrete is well distributed around the perimeter of the core concrete, the distribution of lateral pressure becomes almost uniform; improving the efficiency of confinement reinforcement.

- Closer spacing of transverse reinforcement is known to increase the uniformity of lateral pressure and effectiveness of reinforcement confinement. Concrete columns specimens may don't develop any effect of confinement when the tie spacing was increased to be equal to the section minimum dimension.

- The strength of confined concrete for square column showed better enhancement more than rectangular columns and the enhancement in confined strength decreases by 
increasing the ratio between the long direction and the short direction of rectangular columns.

- Some interactions between test variables were seen in this study. It was observed that the performance of a variable, in contributing to the strength and ductility of confined concrete, varies with the degree of confinement provided by the other variables.

\section{Notations}

$f^{\prime}$ oc : Confined concrete compressive strength in member.

$f_{f^{\prime c o}}^{\prime c 0} \quad$ : Unconfined concrete compressive strength in member

$f_{c}{ }^{\prime c o} \quad$ : Ultimate compressive strength concrete obtained from standard cylinder test

$\mathrm{f}_{\text {test }} \quad$ : Maximum Stress carried by concrete core as observed in test

$f_{y} \cdot$ long : Yield stress for the longitudinal reinforcement

$f y_{\text {ties }}$ : Yield stress for the transversal reinforcement

$\mathrm{P}_{\text {C.C }}$ : Maximum load carried by core concrete

$\mathrm{P}_{\text {Test }} \quad$ : Maximum axial load carried by column as observed in test

$\mathrm{S} \quad$ : Spacing of transverse reinforcement in longitudinal direction.

$\square \quad$ : Volumetric ratio of transverse reinforcement, defined as volume of transverse

\section{REFERENCES} Steel divided by volume of concrete.

[1]. Razvi, S.R., "Confinement of Normal and High-Strength Concrete Columns." Ph.D. Dissertation, Department of Civil Engineering, the University of Ottawa, Ottawa, Ontario, Canada, 1995.

[2]. Karabinis. A. I, and Kiousis, P. D., "Strength and Ductility of Rectangular Concrete Columns A Plasticity Approach”, J. Structural Engineering ASCE, Vol. 122, No. 3, p. 267274 March, 1996.

[3]. P. Paultre, and F. Legreon, "Confinement Reinforcement Design for Reinforced Concrete Columns." Journal of Structural Engineering@ ASCE, MAY 2008, p. 738-749.

[4]. Mander, J. B., Priestley, M. J. N., and Park R., "Theoretical Stress-Strain Model for Confined Concrete," Journal of the Structural Engineering, ASCE, Vol. 114, No. 8, August 1988, p. 1804-1826.

[5]. D. Causson and P. Paultre, "High-Strength Concrete Columns Confined By Rectangular Ties." Journal of Structural Engineering ASCE, Vol. 120, ISSUE 3, p. 783-804 March, 1994. 